\title{
Preconcentration of Lead in Sugar Samples by Solid Phase Extraction and Its Determination by Flame Atomic Absorption Spectrometry
}

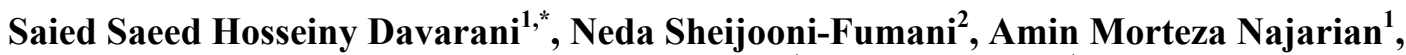 \\ Mohammad-Ali Tabatabaei ${ }^{1}$, Siavash Vahidi ${ }^{1}$ \\ ${ }^{1}$ Department of Chemistry, Faculty of Science, Shahid Beheshti University, GC, Tehran, Iran \\ ${ }^{2}$ Department of Marine Living Resources, Iranian National Institute for Oceanography, Tehran, Iran \\ E-mail: ss-hosseiny@cc.sbu.ac.ir \\ Received May 21, 2011; revised June 27, 2011; accepted July 4, 2011
}

\begin{abstract}
A simple and sensitive solid phase extraction utilizing $\mathrm{C} 18$ filled cartridges incorporated with dithizone for preconcentration of lead and its subsequent determination by flame atomic absorption spectrometry (FAAS) was developed. Several parameters such as type, concentration and volume of eluent, $\mathrm{pH}$ of the sample solution, flow rate of extraction and volume of the sample were evaluated. The effect of a variety of ions on preconcentration and recovery was also investigated. At $\mathrm{pH}=7.4$ and $1.0 \mathrm{~mol} \cdot \mathrm{L}^{-1} \mathrm{HCl}$ eluting them, lead ions were recovered quantitatively. The limit of detection (LOD) defined as $3 \mathrm{~S}_{\mathrm{bl}}$ was determined to be $8.1 \mu \mathrm{g}$ $\mathrm{L}^{-1}$ for $500 \mathrm{~mL}$ of sample solution and eluted with $5 \mathrm{~mL}$ of $1.0 \mathrm{~mol} \cdot \mathrm{L}^{-1} \mathrm{HCl}$ under optimum conditions. The accuracy and precision (RSD \%) of the method were $>90 \%$ and $<10 \%$, respectively. In the end, the proposed method was applied to a number of real sugar samples and the amount of lead was determined by spiking a known concentration of lead into the solution.
\end{abstract}

Keywords: Solid Phase Extraction, Lead, Dithizone, Flame Atomic Absorption Spectroscopy (FAAS), C18 Modified Cartridges

\section{Introduction}

In the past several years, environmental pollution caused by contamination by an assortment of heavy metal ions has become a global problem. Of the heavy metals most harmful for human is lead. Exposure to excessive amounts of lead may cause irreversible neurological damage as well as renal disease and cardiovascular effects [1]. On the top of that, the aforementioned pollutions have found their way in the food-chain and have greater endangered public health [2]. Hence, accurate and sensitive determination of lead in food samples is of prime importance.

Various methods and techniques are utilized for determination of heavy metals in food samples. It is most often done by ICP-OES, ICP-MS, GFAAS and FAAS [3]. Due to its low cost and simplicity, the most commonly used technique for determination of metals in various samples is FAAS. However, FAAS has its own limitations and is particularly circumscribed by its char- acteristic low sensitivity [4-8]. Preconcentration techniques play a pivotal role should FAAS is to be utilized as it improves analytical detection limit, increases sensitivity by several orders of magnitude and enhances accuracy of results [9-10].

Recently a great deal of work has been devoted to solid phase extraction (SPE) as a preconcentration technique. It offers advantages such as short extraction time, low cost, high enrichment factors and recoveries and low consumption of non environment-friendly solvents. SPE can easily be used in tandem with FAAS without much trouble and is generally considered to be a simple method [2,11-16].

Currently, the most common and widely accepted method for determination of lead in sugar samples is ICUMSA's, which is based upon a colorimetric procedure and is suitable for white and raw sugar, as well as low-grade products with lead contents not exceeding 0.5 $\mathrm{mg} \mathrm{Pb} / \mathrm{Kg}$. Although widely accepted and utilized in analysis laboratories, the method involves consumption 
of considerable amounts of highly toxic and dangerous potassium cyanide and perchloric acid. It also consists of procedures that require highly skilled operators. The shortcomings of the current methods and FAAS along with the ever decreasing allowable amount of lead in food products prepare the grounds to develop other methods for determination of lead in sugar samples [12].

The most pivotal step in SPE is considered to be choosing the sorbent material as it gives the method its characteristic properties such as selectivity and capacity towards various metal ions. C18 filled cartridges are still widely used as a sorbent. However, due to its limited ability to absorb metal ions quantitatively at trace and ultra-trace levels, its surface is treated with chelating agents. Besides having the appropriate chelating properties to bond, dithizone has proved to be highly selective towards lead. It also offers high capacity and sensitivity $[13,14]$ and is used for modification of sorbent in this work.

The objective of this paper is to prepare dithizone modified C18 SPE cartridges and investigate its ability to absorb lead by means of FAAS. Despite the fact that rival methods utilizing inductively coupled plasma (ICP) and electrothermal (ET) sample introduction yield slightly better detection limits, this method offers advantages such as simplicity, low cost as well as ease of operation in comparison with those mentioned above. Conditions such as $\mathrm{pH}$, eluent volume, concentration, flow rate of elution, and sample volume were optimized. Finally, the amount of lead in real sugar samples is determined.

\section{Experimental}

\subsection{Apparatus}

Concentration of $\mathrm{Pb}$ (II) ions were determined by an AA680 Shimadzu (Kyoto, Japan) flame atomic absorption spectrometer (FAAS) in an air-acetylene flame, according to the user's manual provided by the manufacturer. A lead Hollow cathode lamp was used as the radiation source with wavelength set at $217.0 \mathrm{~nm}$. pH adjustments were carried out by a Metrohm model-627 (Herisau, Switzerland) pH-Meter. Sep-Pak C18 cartridges produced by Waters (USA, Florida) containing $500 \mathrm{mg}$ of octadecylsilane served as solid phase and a Rocker 600 (Todays, Taiwan) was also utilized in the process.

\subsection{Reagents and Materials}

All reagents were of the analytical-reagent grade. The stock standard solution $\left(1.000 \mathrm{~g} \cdot \mathrm{L}^{-1}\right)$ of $\mathrm{Pb}^{2+}$ was obtained from E. Merck (Darmstadt, Germany) and was diluted with deionized water. A $50 \mathrm{~g} \cdot \mathrm{L}^{-1}$ solution of lead was prepared and working standard solutions of lead were prepared by diluting a proper amount of the aforementioned solution. Dithizone was dissolved in chloroform; both reagents were purchased from E. Merck (Darmstadt, Germany). $1.0 \mathrm{~mol} \cdot \mathrm{L}^{-1}$ solution of $\mathrm{HCl}$ was prepared by appropriate dilution of stock solution of concentrated hydrochloric acid in deionized water. Buffer solutions with different $\mathrm{pH}$ were prepared by dissolving appropriate amounts of suitable salts salt purchased from E. Merck (Darmstadt, Germany) and Fluka (Switzerland) in deionized water. Sugar was acquired from the grand market of Tehran.

\subsection{Cartridge Modification}

Each cartridge was washed with $5 \mathrm{~mL}$ of ethanol, $10 \mathrm{~mL}$ of water followed by $5 \mathrm{~mL}$ of $1.0 \mathrm{~mol} \cdot \mathrm{L}^{-1} \mathrm{HCl}$ and then another $10 \mathrm{~mL}$ of deionized water in order to remove all the potential contaminants as a result of the manufacturing process. The cartridge was then dried by passing air through it for a few minutes. $2.0 \mathrm{~mL}$ of dithizone solution $\left(1000 \mathrm{mg} \cdot \mathrm{L}^{-1}\right.$ in chloroform) was left in the cartridge and allowed to penetrate inside the pores of the solid phase. The solvent was allowed to evaporate at $60^{\circ} \mathrm{C}$ for 30 minutes. Subsequently, air was passed through the cartridge for a several minutes to ensure that it is thoroughly dried.

\subsection{General Procedure}

The extraction process was carried out by passing solutions containing $\mathrm{Pb}^{2+}$ ions through the cartridge. Backextraction was done by eluting the cartridge with $5.0 \mathrm{~mL}$ of $1.0 \mathrm{~mol} \cdot \mathrm{L}^{-1} \cdot \mathrm{HCl}$. At the end, the lead content of the samples were determined by FAAS.

\subsection{Application to Sugar Samples}

50.000 grams of sugar was dissolved in $500 \mathrm{~mL}$ of ammonium acetate solution $(\mathrm{pH}=7.4)$. Solid phase extractions were performed on the samples by passing the solution through the modified cartridge. Back-extractions were performed by eluting the lead content by $5.0 \mathrm{~mL}$ of $1.0 \mathrm{~mol} \cdot \mathrm{L}^{-1} \cdot \mathrm{HCl}$.

\section{Results and Discussion}

\subsection{Adsorption Properties of Cartridge and Ligand}

Solutions of known concentration of lead were passed through the column which contained only $\mathrm{C} 18$. The results indicated that less than $5 \%$ of $\mathrm{Pb}^{2+}$ ions were re- 
tained by the cartridge. After modifying the C18 support by dithizone, the tendency of the cartridge to absorb the ions increased considerably. This increase can be attributed to the complex formation between the ligand and the lead ion (Figure 1). In order to maximize the absorption capability of the modified cartridge, the SPE conditions were optimized one at a time.

\subsection{Type of Eluent}

Due to the intrinsic properties of ligand, an acidic solution is required for the lead ions to be desorbed. An acidic solution protonates the chelating sites and elutes the cartridge of $\mathrm{Pb}^{2+}$ ions. The criteria for eluent selection were strength of acid, its availability in laboratories and green chemistry considerations. Nitric acid $\left(\mathrm{HNO}_{3}\right)$, hydrochloric acid $(\mathrm{HCl})$, acetic acid $\left(\mathrm{CH}_{3} \mathrm{COOH}\right)$ and ethanol were investigated to be utilized as eluent. Being an organic solvent, elution by ethanol lead to recoveries over $100 \%$. However, in addition to $\mathrm{Pb}^{2+}$ ions, it eluted the ligand as well. Among acid solutions, acetic acid exhibited substantially lower recovery than the other two. Among nitric acid and hydrochloric acid, hydrochloric acid yielded higher recoveries. Hence; $\mathrm{HCl}$ was chosen as eluent.

\subsection{Concentration and Volume of Eluent}

In order to determine the optimized eluent concentration, $100.0 \mathrm{~mL}$ aliquots of samples solu tions containing 0.05 $\mathrm{mgL}^{-1}$ of $\mathrm{Pb}^{2+}$ were passed through the cartridge and were eluted with $5 \mathrm{~mL}$ of $\mathrm{HCl}$ having different concentrations. As indicated in Figure 2, recovery of $\mathrm{Pb}^{2+}$ increased up to $1.0 \mathrm{~mol} \cdot \mathrm{L}^{-1}$ but decreased with further increase of concentration as more concentrated acid destroys and hydrolyses the solid support. Thus $1.0 \mathrm{~mol} \cdot \mathrm{L}^{-1}$ $\mathrm{HCl}$ was chosen as the optimum concentration of eluent.

Also the volume of the eluent was optimized in the process. The range from $1.0 \mathrm{~mL}$ to $10.0 \mathrm{~mL}$ of eluent volume was investigated and the results indicated that no considerable increase in recovery was achieved by increasing the eluent volume beyond $5.0 \mathrm{~mL}$. So the volume of $5.0 \mathrm{~mL}$ was employed in this work. (Figure 3)

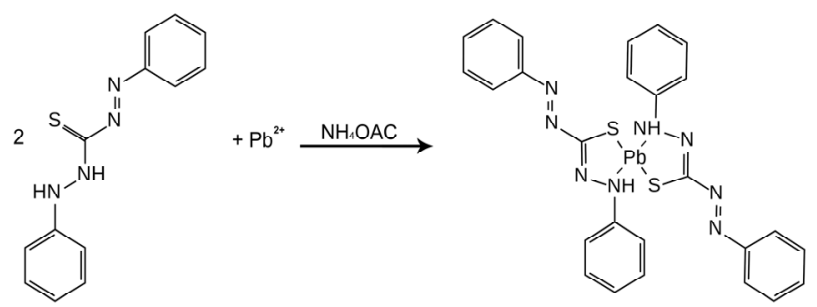

Figure 1. Structure of ligand and the coordination compound it forms.

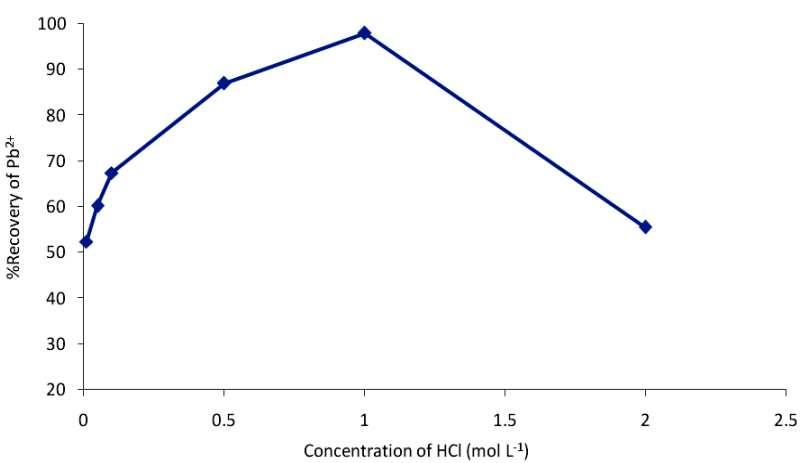

Figure 2. Effect of concentration of $\mathrm{HCl}$ on the recovery of $\mathrm{Pb}^{+2}$. Conditions: Sample volume: $100 \mathrm{~mL}$, amount of dithizone: $2.0 \mu \mathrm{g}$, sample flow rate: $15 \mathrm{~mL} \cdot \mathrm{min}^{-1}$, eluent flow rate: $15 \mathrm{~mL} \cdot \mathrm{min}^{-1}$, eluent volume: $5 \mathrm{~mL}$, $\mathrm{pH}$ of sample solution: 7.4 .

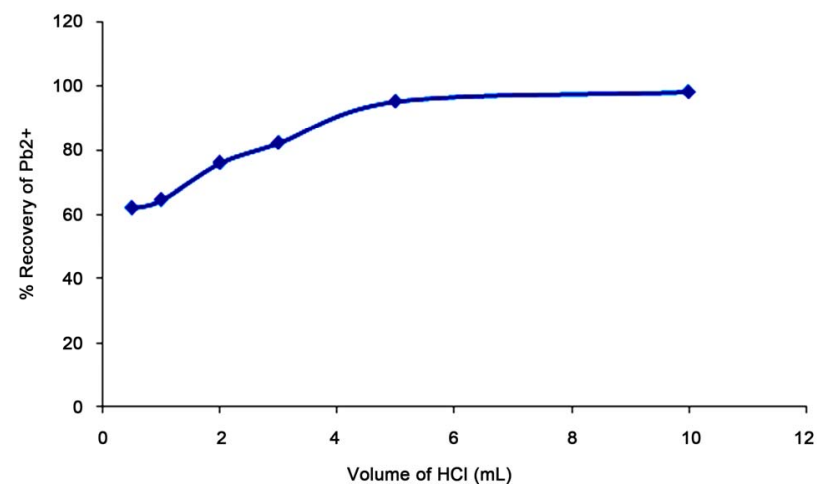

Figure 3. Effect of volume of $\mathrm{HCl}$ on the recovery of $\mathbf{P b}^{+2}$. Conditions: Sample volume: $100 \mathrm{~mL}$, amount of dithizone: $2.0 \mu \mathrm{g}$, sample flow rate: $15 \mathrm{~mL} \cdot \mathrm{min}^{-1}$, eluent flow rate: 15 $\mathrm{mL} \cdot \mathrm{min}^{-1}$, eluent concentration: $1.0 \mathrm{~mol} \cdot \mathrm{L}^{-1}, \mathrm{pH}$ of sample solution: 7.4 .

\subsection{Effect of pH}

Since adsorption of lead ions occurs as a result of formation of a coordination compound, $\mathrm{pH}$ has a profound effect on the retention of the ions by the ligand. C18 undergoes acidic hydrolysis at $\mathrm{pH}$ under 2 and its silica structure is prone to dissolution at pHs above 8 (Dong, 2006) thus $\mathrm{pH}=1$ was discarded during optimization. Optimization of $\mathrm{pH}$ was carried out (Figure 4) and based on the results $\mathrm{pH}=7.4$ were chosen as optimum $\mathrm{pH}$. Dithizone is a bidentate chelating agent and possesses two coordination sites; sulfur and nitrogen. Thus, when the concentration of hydronium ion increases, the more susceptible site to protonation, i.e. nitrogen, is unable to bond to lead ions, hence reduced retention. Higher values of $\mathrm{pH}$ causes the problem of precipitation of lead in the form of $\mathrm{Pb}(\mathrm{OH})_{2}$. The aforementioned $\mathrm{pH}$ value was adjusted by addition of $\mathrm{NH}_{3}$ and $\mathrm{HCl}$ solutions and was later stabilized using a $1.0 \mathrm{~mol} \cdot \mathrm{L}^{-1}$ ammonium acetate solution. 


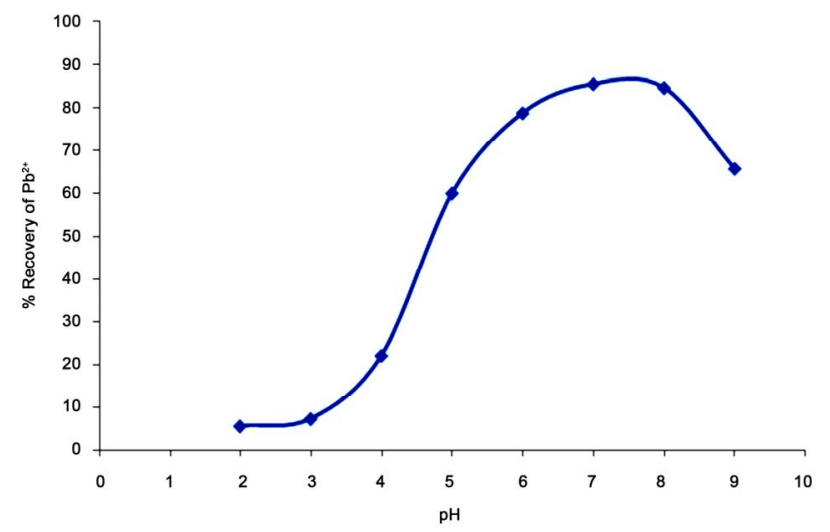

Figure 4. Effect of $\mathrm{pH}$ of sample solution on the recovery of $\mathrm{Pb}^{+2}$. Conditions: sample volume: $100 \mathrm{~mL}$, amount of dithizone: $2.0 \mu \mathrm{g}$, sample flow rate: $15 \mathrm{~mL} \cdot \mathrm{min}^{-1}$, eluent flow rate: $15 \mathrm{~mL} \cdot \mathrm{min}^{-1}$, concentration of eluent: $1.0 \mathrm{~mol} \cdot \mathrm{L}^{-1}$, eluent volume: $5 \mathrm{~mL}$.

\subsection{Flow Rate Optimization}

The potential implications caused by the flow rate of the solution through the cartridge and flow rate of elution were examined. Solid phase extraction was conducted on solutions with known quantities of lead while altering the flow rate in the range of $5-25 \mathrm{~mL} / \mathrm{min}$. Retention depressed at least $20 \%$ with $5 \mathrm{~mL} / \mathrm{min}$ increments of flow rate beyond $15 \mathrm{~mL} / \mathrm{min}$ in both cases. Thus, the fastest flow rate with the best recovery was determined to be 15 $\mathrm{mL} / \mathrm{min}$.

\subsection{Dilution and Kinetic Effect}

One of the parameter to be optimized is the kinetic effect of adsorption on the ligand. By diluting the solution, more time is being given to the ions to be adsorbed on the ligand. To study this effect, $10 \mu \mathrm{g}$ of $\mathrm{Pb}^{2+}$ was dissolved in volumes of ammonium acetate solution in the range of $50-1000 \mathrm{~mL}$. A sharp improvement in recovery was detected in the early stages but no considerable improvement was observed upwards of $100 \mathrm{~mL}$ mark. Although volumes as high as $500 \mathrm{~mL}$ can be used to yield high enrichment factors, a sample volume of $100 \mathrm{~mL}$ can be utilized with no sizeable decrease in recovery.

\subsection{Interferences}

To assess the application of the proposed solid phase extraction to real samples, effects of some interfering ions which may enter sugar merchandise during the course of production such as arsenic, iron, magnesium, cobalt, zinc, and copper were investigated under the optimized conditions. A fixed amount of $\mathrm{Pb}$ (II) ions was taken with a known concentration of the aforementioned foreign ions and their effect on the recovery of $\mathrm{Pb}(\mathrm{II})$ was investigated. Those effects on solid phase extraction were totally negligible and were also suitable for atomic absorption spectrometric determinations and did not cause any type of difficulty or implication.

\subsection{Figures of Merit}

The analytical performance of the method was evaluated by plotting a calibration curve with 6 standard solutions. The calibration curve was linear in the range of $27-200$ $\mu \mathrm{g} \cdot \mathrm{L}^{-1}$ with a correlation coefficient equal to 0.9910 . The standard deviation of the method was determined by conducting eight replicate analysis and proved to be smaller than $10 \%$. The limit of detection (LOD) and limit of quantification (LOQ) of the method, defined equal to three and ten times the standard deviation of the blank and when preconcentration factor equals 100 , were determined to be $8.1 \mu \mathrm{g} \cdot \mathrm{L}^{-1}$ and $27 \mu \mathrm{g} \cdot \mathrm{L}^{-1}$, respectively. Values as low as $4.2 \mu \mathrm{g} \cdot \mathrm{L}^{-1}$ and $14 \mu \mathrm{g} \cdot \mathrm{L}^{-1}$ are achievable should a preconcentration factor of 200 is applied.

\subsection{Application to Sugar Samples}

The proposed method was applied to sugar samples. 50.000 grams of sugar was weighted and dissolved in $500.0 \mathrm{~mL}$ of ammonium acetate solution. The samples were passed through the cartridge. After elution by $5 \mathrm{ml}$ of $1.0 \mathrm{~mol} \cdot \mathrm{L}^{-1} \mathrm{HCl}$, the lead concentration in the samples was determined by FAAS. To establish the accuracy of the peaks, sugar samples were spiked with known amounts of lead and the proposed SPE method was applied. The results (Table 1) showed good agreement with the ones obtained from the simple standard technique.

\section{Conclusions}

The proposed method provides an effective approach towards preconcentration of $\mathrm{Pb}^{2+}$ ions in sugar samples. The method is simple, rapid and reliable in comparison with rival methods (Table 2). The analytical performance and figures of merit, namely; relative standard deviation, LOD, LOQ and recovery for this method are either better or comparable to other methods and involves minimal usage of solvents and chemicals that are

Table 1. Determination of lead in sugar samples by the proposed method.

\begin{tabular}{cccc}
\hline $\begin{array}{c}\text { Sample } \\
\text { i.d. }\end{array}$ & $\begin{array}{c}\text { Amount added } \\
\mathrm{Pb}^{2+}(\mathrm{ppb})\end{array}$ & $\begin{array}{c}\text { Amount found } \mathrm{Pb}^{2+} \\
(\mathrm{ppb})( \pm \% \mathrm{RSD})\end{array}$ & $\begin{array}{c}\text { Extraction } \\
( \pm \% \mathrm{RSD})\end{array}$ \\
\hline a Sugar & - & $<20$ & - \\
Sugar & 50 & $45( \pm 3)$ & $90( \pm 6)$ \\
\hline
\end{tabular}


Table 2. Figures of merit of comparable methods for determination of lead.

\begin{tabular}{lcccc}
\hline \multicolumn{1}{c}{ Reagent } & LOD $\left(\mu \mathrm{g} \cdot \mathrm{L}^{-1}\right)$ & Maximum enrichment factor & Technique & References \\
\hline 3-Aminopropyltriethoxysilane modified silica gel & 4.00 & - & GFAAS $^{\mathrm{a}}$ & {$[16]$} \\
8-Hydroxyquinoline immobilized on controlled pore glass & 8.27 & - & IC $^{\mathrm{b}}$ & {$[17]$} \\
Cellulose sorbent with phosphoric acid groups (Cellex P) & 1.8 & 197 & FAAS & {$[18]$} \\
Silica gel functionalized with methylthiosalicylate & 15.30 & 41 & ICP-OES & {$[19]$} \\
Silica Gel (Pb-02) & 5.0 & 52 & FAAS & {$[20]$} \\
Dithizone & 4.4 & 200 & FAAS Present Work
\end{tabular}

${ }^{\mathrm{a}}$ Graphite furnace atomic absorption spectroscopy; ${ }^{\mathrm{b}}$ Ion chromatography; ${ }^{\mathrm{c}}$ Flame atomic absorption spectroscopy; ${ }^{\mathrm{d}}$ Electro thermal atomic absorption spectroscopy; e Inductively coupled plasma optical emission spectroscopy.

not environmentally friendly. The high preconcentration factor and precision of this method as well as its satisfactory reproducibility makes it applicable to sugar samples in which their lead content is below the detection limit of FAAS.

\section{Acknowledgements}

Financial support for this work by the Research Affairs, Shahid Beheshti University, is gratefully acknowledged.

\section{References}

[1] M. Ghaedi, F. Ahmadi and A. Shokrollahi, "Simultaneous Preconcentration and Determination of Copper, Nickel, Cobalt and Lead Ions Content by Flame Atomic Absorption Spectrometry," Journal of Hazardous Materials, Vol. 142, No. 1-2, 2007, pp. 272-278. doi:org/10.1016/j.jhazmat.2006.08.012

[2] Zh. Lia, X. Changa, X. Zoua, R. Niea, Zh. Hua and R. Lia, "Chemically-Modified Activated Carbon with Ethylenedia-Mine for Selective Solid-Phase Extraction and Preconcentration of Metal Ions," Analytica Chimica Acta, Vol. 632, No. 2, 2009, pp. 272-277. doi:org/10.1016/j.aca.2008.11.001

[3] T. Oymak, S. Tokalio, V. Yilmaz, S. Kartal and D. Aydin, "Determination of Lead and Cadmium in Food Samples by the Coprecipitation Method," Food Chemistry, Vol. 113, No. 4, 2009. pp. 1314-1317.

[4] J. Koh, Y. Kwon and Y. N. Pak, "Separation and Sensitive Determination of Arsenic Species $\left(\mathrm{As}^{3+} / \mathrm{As}^{5+}\right)$ Using the Yeast-Immobilized Column and Hydride Generation in ICP-AES," 2 nd Edition, Changwon Symposium on Advanced Science and Technology, Vol. 80, 2005, pp. 195-199.

[5] Y. K. Agrawal and K. R. Sharma, "Speciation, Liquid-Liquid Extraction, Sequential Separation, Preconcentration, Transport and ICP-AES Determination of $\mathrm{Cr}$ (III), Mo(VI) and W(VI) with Calix-Crown Hydroxamic Acid in High Purity Grade Materials and Environmental Samples," Talanta, Vol. 67, 2005, pp.120-122.

[6] M. Zeiner, I. Steffan and I. J. Cindric. "Determination of
Trace Elements in Olive Oil by ICP-AES and ETA-AAS: A Pilot Study on the Geographical Characterization," Microchemical, Vol. 81, 2005, pp. 171-176.

[7] K. H. Lee, Y. Muraoka, M. Oshima and S. Motomizu, "Determination of Heavy Metals and Rare Earth Elements in Environmental Samplesby ICP-MS after Solid Phase Preconcentration with Chelating Resin Fibersand Anion Exchange Filters," Analytical Sciences, Vol. 20, No. 1, pp. 183. doi:org/10.2116/analsci.20.183

[8] G. Xiang, Y. Huang and Y. Luo, "Solid Phase Extraction of Trace Cadmium and Lead in Food Samples Using Modified Peanut Shell Prior to Determination by Flame Atomic Absorption Spectrometry," Microchim Acta, Vol. 165, No. 1-2, 2009, pp. 237-242.

[9] M. Korn, J. Andrade, D. Jesus, V. Lemos, M. Bandeira, W. dos Santos, M. Bezerra, F. Amorim, A. Souza and S. Ferreira, "Separation and Preconcentration Procedures for the Determination of lead Using Spectrosppuc Techniques: A Review," Talanta, Vol. 69, 2006, pp. 16-24.

[10] M. Tuzena, M. Soylakb and L. Elcic, "Multi-Element Preconcentration of Heavy Metal Ions by Solid Phase Extraction on Chromosorb 108," Analytica Chimica Acta, Vol. 548, No. 1-2, 2005, pp. 101-108. doi:org/10.1016/j.aca.2005.06.005

[11] C. F. Poole, "New Trends in Solid-Phase Extraction," Trends in Analytical Chemistry, Vol. 22, No. 6, 2000, pp. 362- 373. doi:org/10.1016/S0165-9936(03)00605-8

[12] ICUMSA, "Department of British Sugar," International Commission for Uniform Method of Sugar Analysis, 2007.

[13] N. Burham, S. M. Abdel-Azeem and F. El-Shahat, "Determination of Lead and Cadmium in Tap Water and Apple Leaves after Preconcentration on a New Acetylacetone Bonded Polyurethane Foam Sorbent," International Journal of Environmental Analytical Chemistry, Vol. 88, No. 11, 2008, pp. 775-789. doi:org/10.1080/03067310801958692

[14] M. Soylak, I. L. Elc and M. Do־gan, "Determination of Some Trace Metal Impurities in Refined and Unrefined Salts after Preconcentration onto Activated Carbon," Fresenius Environment Bull, Vol. 5, 1996, pp. 148-155.

[15] M. W. Dong, "Modern HPLC for Practicing Scientists: John Wiley \& Sons," 2009, pp. 59-60. 
[16] C. Ekinci and Ü. Köklü, "Determination of Vanadium, Manganese, Silver and Lead by Graphite Furnace Atomic Absorption Spectrometry after Preconcentration on Silica-Gel Modified with 3-Aminopropyltriethoxysilane," Spectrochimica Acta Part B: Atomic Spectroscopy, Vol. 55, No. 9, 2000, pp. 1491-1495. doi:org/10.1016/S0584-8547(00)00259-7

[17] M. R. B. Abas, I. A. Takrunia, Z. Abdullaha and M. M. Tahirb, "On-Line Preconcentration and Determination of Trace Metals Using a flow Injection System Coupled to Ion Chromatography," Talanta, Vol. 58, No. 5, 2002, pp. 883-890. doi:10.1016/S0039-9140(02)00396-X

[18] K. Pyrzyska and K. Cheregi, "Lead Determination with
On-Line Enrichment System," Water Research, Vol. 34, No. 17, 2000, pp. 4215-4219.

doi:org/10.1016/S0043-1354(00)00198-6

[19] M. Zeiner, I. Steffan and I. J. Cindric. "Determination of Trace Elements in Olive Oil by ICP-AES and ETA-AAS: A Pilot Study on the Geographical Characterization," Microchemical, Vol. 81, No. 2, 2005, pp. 171-176.

[20] M. Zougagh, A. García de Torres, E. V. Alonso and J. M. C. Pavón, "Automatic on Line Preconcentration and Determination of Lead in Water by ICP-AES Using a TS-Microcolumn," Talanta, Vol. 62, No. 3, 2004, pp. 503-510. 